\title{
LA MÚSICA COMO RECURSO DIDÁCTICO EN EDUCACIÓN FÍSICA
}

\section{Autores}

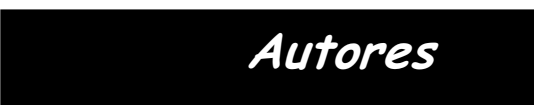

FACULTAD DE CIENCIASDEL

BEGONA LEARRETA RAMOS

UNIVERSIDAD EUROPEA DEMADRID

begona.learreta@uem.es

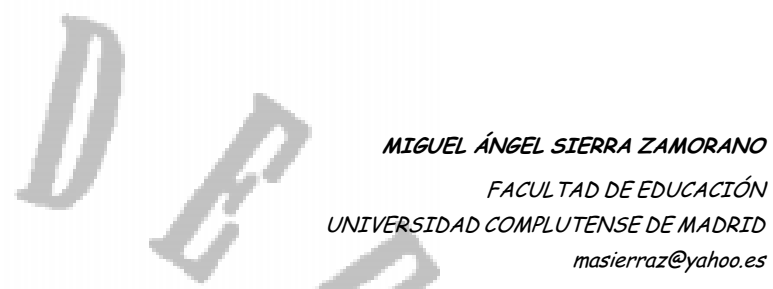

\section{RESUMEN}

En nuestra opinión, en los últimos tiempos, el profesorado de Educación Física está utilizando cada vez con menor frecuencia la música como recurso didáctico en el desarrollo de sus actividades docentes. Sin embargo creemos que la música puede serle de gran ayuda, tanto desde el punto de vista de motivación extrínseca como de recurso metodológico. Además la música forma parte consustancial de la vida de nuestro alumnado.

Este artículo pretende ser una guía para invitar al profesorado de Educación Física a utilizar la música como recurso didáctico significativo a la hora de preparar sus sesiones. En él se habla sobre los efectos de la música sobre el organismo, el lugar que la misma ha ocupado en la historia de nuestra materia, de las funciones que la música puede cumplir en nuestras clases, de la sistematización de su uso y de los procedimientos para su selección y utilización.

\section{PALABRAS CLAVES}

Didáctica, Educación Física y música.

\section{Introducción}

Desde nuestros planteamientos didácticos en el ámbito de la Educación Física (entendemos por ésta la parte de la educación integral del ser humano que tiene como fin el desarrollo y perfeccionamiento de todas sus capacidades, utilizando como medio fundamental el cuerpo en todas sus posibilidades), consideramos que la música puede ser un recurso metodológico de gran importancia. Son muchas y variadas las funciones que puede tener, y por consiguientes muy diversos sus usos y aplicaciones en el seno de las sesiones de nuestra materia.

Creemos que en la formación inicial del profesorado de Educación Física hay un vacío importante al respecto. Quizá la razón de ello sea que existen prejuicios respecto al uso de la música en las clases, basados en popularizar y reconocer tan sólo unas dimensiones muy limitadas de sus posibilidades. Sin embargo se acepta, de forma generalizada, la necesidad de impartir ciertos contenidos asociados a la música, como son los bailes o las danzas. Creemos que es éste exclusivamente el valor que se le reconoce, lo cual nos parece una visión muy limitada y reduccionista de sus posibilidades.

Reivindicamos con firmeza el uso de la música en las clases de Educación Física: para romper con estos estereotipos; para mejorar nuestras prácticas docentes; para generar más entusiasmo en nuestro alumnado; para apor- tar innovación en algunos casos; y para darle a nuestro trabajo un carácter más multidisciplinar, acorde con nuestros planteamientos pedagógicos.

En la actualidad, y cada vez con más frecuencia, salen a la luz nuevas prácticas que vinculan, de forma significativa, de una u otra manera, el movimiento y la música, como el 'Aeróbic' y todos sus derivados. Parece obvio que la actividad física asociada a la música tiene una respuesta positiva en quienes la practican. Estas prácticas que el público demanda se van imponiendo gracias a su demanda mayoritaria. Este hecho podría ser el dato que pondría de manifiesto el éxito del binomio movimientomúsica, algo ya totalmente integrado en nuestra cultura, y que los profesionales de la Educación Física deberíamos intentar reincorporar a nuestro quehacer pedagógico.

Para terminar esta breve introducción expondremos los dos objetivos fundamentales de este pequeño ensayo:

1) Proponer una mejora en nuestra intervención docente por medio de la utilización de la música como recurso didáctico en nuestras clases de Educación Física; y

2) Ofrecer al profesorado las herramientas que faciliten el uso de la música en sus clases de Educación Física. 


\section{Justificación del uso de la Música en las clases de Educación Física}

la mayor representación de ello por tener la capacidad de generar estados de ánimo en quienes la escuchan.

En esta misma línea Beltrán (1991) expone que la música, dependiendo de sus cualidades particulares: melodía, ritmo, armonía, timbre y forma nos afecta emocionalmente despertando en la persona un sentido anímico, a pesar de que lo hace en cada individuo de forma distinta porque cada sujeto tiene diferentes tendencias mentales y emocionales. Esto representa el sentido anímico de la música pero además, la música posee un sentido imitativo. Es capaz de sugerir imágenes mentales: un paisaje bucólico, el viento, una tormenta, etc. Muchos elementos naturales pueden ser 'representados' por combinación de los elementos musicales y no necesariamente de una forma real, sino a través de la expresión artística propia de este arte.

Tanto desde un punto de vista antropológico como etnológico puede decirse que actividad física y música han ido siempre unidas. El acunar al bebé se asocia instantáneamente a la nana, los juegos infantiles a las ratahílas y las canciones de corro, los desfiles militares a las marchas, y buena parte de los labores con gran desgaste energético, ahora más suavizados, a las canciones de trabajo (de boga, de forja [el martinete], de mina [mineras], de siega, de trilla, etc.)

El ser humano descubrió muy pronto la correlación directa entre el desarrollo de sus movimientos corporales y los elementos del sonido que configuran la música, y se dio cuenta que al conexionar ambas actividades, apoyando el esfuerzo físico en el ritmo de la música, ésta le servía de alivio y ayuda para aquél.

Por todo ello, el uso de la música en las clases de Educación Física, cuando ésta ha sido convenientemente seleccionada con anterioridad, puede constituir una importante ayuda para el profesorado. Contribuye a mejorar y facilitar la enseñanza, motivo por el cual su uso puede ser considerado como un importante recurso didáctico capaz de mejorar nuestra enseñanza.

\subsection{Efectos de la Música en el organismo}

Como señalan Pareti, Brezzi y Petech $(1981,274)$ "desde tiempos primitivos el hombre sintió la necesidad de ampliar los sonidos que emitía influido por la emoción y de procurarles énfasis y exaltación", y recíprocamente, tomó conciencia de que la música le emocionaba, exaltándole o tranquilizándole.

En la actualidad, según Michels $(1992,13)$, "la psicología de la música se ocupa de los efectos producidos por la música y por la obra de arte musical sobre el hombre." Y así, muy frecuentemente, se afirma que la música es una de las actividades más culturales de los seres humanos, por ser la que más directamente va a la sensibilidad, a las emociones y a los sentimientos, y por lo tanto menos necesita de ninguna intelectualización. Bourdieu (1998) afirma que el arte es algo corporal y la música es
Por otra parte podemos decir que las primera investigaciones psicofisiológicas en torno a la música, de que tenemos noticia, la primera editada en 1863 y debida a Helmholtz, ya ponían de manifiesto la vinculación entre música y sentimiento, y unos años más tarde Riemann volvería a considerar la música como "un medio expresante de los movimientos más íntimos del ánimo humano" (citado por Fubini, 2002, 342), llegando a afirmar que "comunica, de manera más directa y perfecta que cualquier otro arte, los sentimientos más íntimos" (Ibid., 343.)

Estas investigaciones llegaron a incluir, a principios de siglo, la utilización de técnicas científicas aplicadas al campo de la fisiología, para medir los cambios que producía la música en el organismo humano, y así Hyde, en 1927, concluía que "se ha descubierto que las funciones cardiovasculares son estimuladas de un modo reflejo junto con los efectos psicológicos de la música, y que utilizando el galvanómetro de hilo de Einthoven y esfigmomanómetros sensibles, se pueden medir y comparar las reacciones fisiológicas que producen los distintos géneros musicales" (citada por Swanwick, 1992, 24-25.)

En 1933, Vernon (citado por Swanwick, Ibid., 28), llegó a elaborar una lista de siete categorías en relación con las respuestas que las personas pueden dar frente a la música: Física (la sensación real de sonido); Procesos libres de pensamiento (soñar despierto con la música); Reacción emocional (especialmente asociaciones dramáticas o visuales); Reacción emocional (incluyendo los delicados y comple jos ajustes que acompañan a cada percepción); Sinestesia (sobre todo la unión de clave musical y color visual); Imágenes auditivas y procesos intelectuales (analíticos y técnicos); Factores sociales y temperamentales."

Además, y como ya hemos visto, la música sugiere también toda una serie de sensaciones corporales. Michels $(1992,21)$, refiriéndose a la psicología de la audición musical, expone que surgen otras dimensiones psicológico-musicales, como el volumen, el peso y la densidad ya que los tonos graves se consideran grandes, voluminosos y abombados, pesados torpes y corpulentos, porosos, obtusos y blandos, mientras que los tonos agudos se consideran pequeños, estrechos y delgados, etéreos, livianos y ágiles, aguzados, firmes y angulosos. 


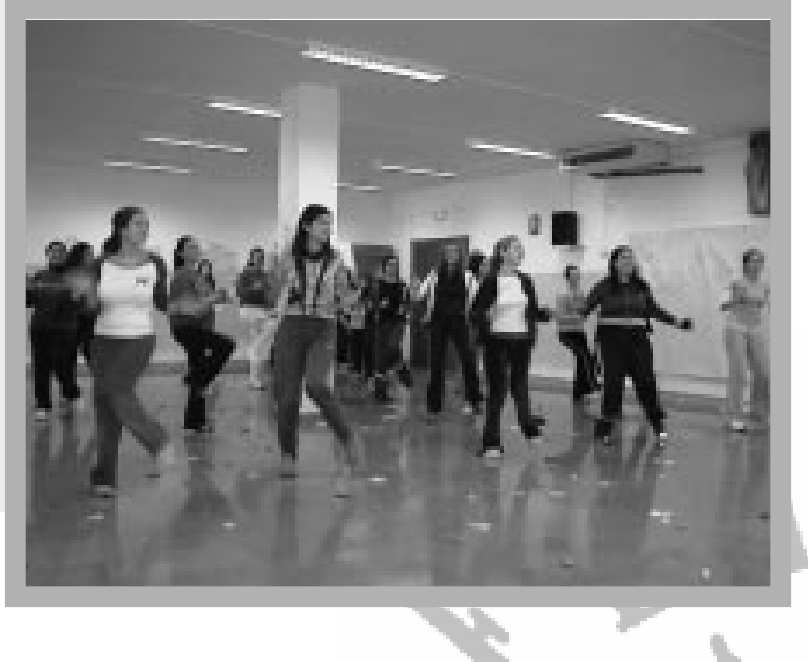

Con estas ideas pretendemos poner de manifiesto, tal y como expone Meyer (2001), que es un hecho la incidencia de la música sobre estados anímicos, y de éstos sobre funciones fisiológicas. Esta realidad es una razón de gran peso para utilizar la música en las clases de Educación Física. Gracias a ella podemos incidir en la disponibilidad del alumnado, en su estado anímico, en su interés hacia el trabajo, etc., lo cual va a revertir positivamente en el proceso de enseñanzaaprendizaje.

\subsection{La Música en la Historia de la Educación Física}

Otra razón que nos ha hecho reflexionar en el sentido de retomar el uso de la música en las clases de Educación Física es echar la vista atrás y reconocer que la utilización de la música en el ámbito de la Educación Física, como recurso metodológico, tiene una amplia y rica tradición histórica que hunde sus raíces hasta la más remota antigüedad.

En la antigua Grecia tanto la práctica de la actividad física como las competiciones deportivas eran acompañadas con música. En los gimnasios griegos los ejercicios físicos eran practicados al son del aulos (oboe) o la cítara (lira), y en los antiguos Juegos Olímpicos durante las pruebas del salto del pentatlón se tocaba la melodía de la flauta pítica.

Posteriormente tendríamos que esperar hasta el Renacimiento para poder volver a encontrar la actividad física como parte de la educación, y a la música junto con ella. Así, por ejemplo, tanto Elyot (UImann, 1997), como posteriormente Mercurial (1969-70) hablan de la danza como parte importante de la gimnasia.

Durante la Reforma, la Contrarreforma y el Absolutismo, es decir, en los períodos de la historia en que se fraguaron los orígenes de la actual Educación Física, también ambas materias marcharon hermanadas. Tanto Montaigne, Rousseau y Noverre, como La Condamine y Pestalozzi, utilizaban indistintamente la música, la danza y el canto (según Burgener,1973.)
La época de la Restauración fue donde nacieron y se desarrollaron las escuelas gimnásticas (alemana, sueca y francesa) y el deporte moderno en Inglaterra. Podría decirse, que como derivaciones fundamentales, primero del naturalismo y después del romanticismo, los filántropos eran amantes de la naturaleza y de los seres humanos por extensión, de la actividad física, del folklore (costumbres, juegos, música popular y tradicional, etc.), de la infancia y de su mundo, de la libertad, del idealismo, la espontaneidad, la pasión, etc.

Pero quizá fue durante la época de los Imperialismo y de las dos Grandes Guerras, es decir durante la primera mitad del siglo $X X$, cuando más conjuntadas estuvieron la Educación Física y la música.

A principios del siglo $X X$, la influencia de la danza sobre la Educación Física, y viceversa fue considerable. Como señalan Langlade y Rey $(1986,89)$, "es necesario destacar que en 1925, la 'Liga de Gimnasia Alemana' surgida como consecuencia del Congreso de Berlín de 1922, estaba integrada entre otros por Bode, Gindler, Kallmeyer, Laban, Loheland y Mensendieck."

Durante la segunda mitad del siglo XX, el deporte, que siempre había tenido un papel predominante en Inglaterra, experimento un desarrollo y una evolución espectacular, favorecido por la revitalización de los Juegos Olímpicos, debida a Coubertin, irrumpiendo en el ámbito de la Educación Física con una fuerza arrolladora. No por eso la música dejó de estar presente en las sesiones de Educación Física. Listello (Varios, 1964), uno de los más fervientes defensores del método deportivo en Francia, utilizaba el canto, la danza y algunos instrumentos musicales en sus sesiones de Educación Física. En Alemania, entre otros, Dieckert, Kreiss y Meusel (Varios, 1972), destacados representantes también del método deportivo, propugnaban asimismo la utilización de las danzas y la música en su método.

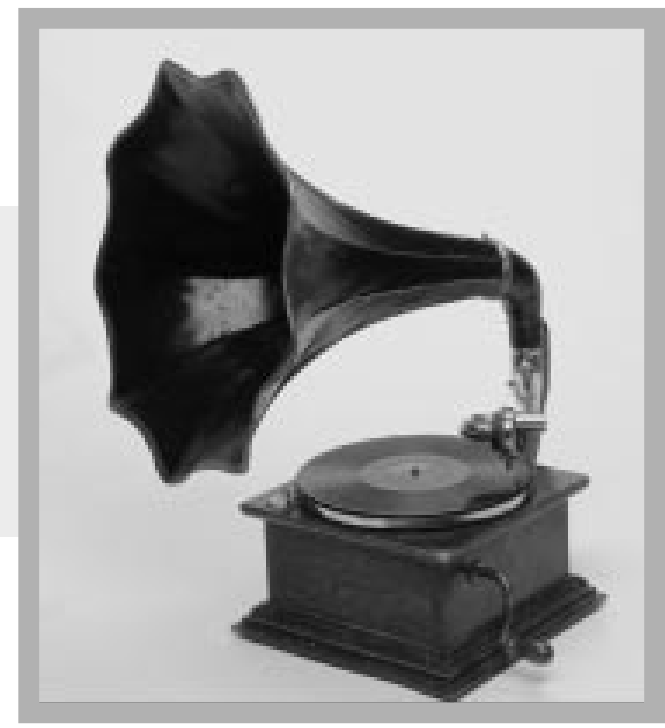

Aquí hemos de señalar, que, como en la antigua Grecia, algunas modalidades deportivas también emplean la música: Gimnasia Artística (Ejercicios de Suelo en la modalidad femenina), Gimnasia Rítmica, Hípica (Doma), Natación Sincronizada, Patinaje Artístico sobre hielo, Patinaje Artístico sobre ruedas, etc. 


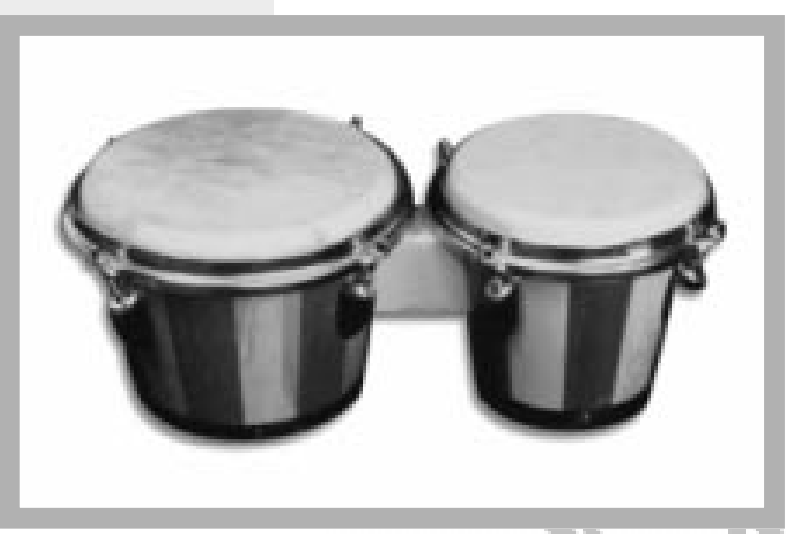

Si bien la danza (sobre todo en su vertiente folclórica o tradicional), siempre estuvo unida a la gimnasia, desde sus más remotos inicios, como ya hemos visto al principio, en los últimos años, no sólo ésta (la folclórica), sino también la más popular y moderna (chachachá, mambo, merengue, pasodoble, rumba, tango, rock, vals, etc.), es decir, los que han dado en llamarse 'Bailes de salón', han irrumpido con gran fuerza en el campo de la Educación Física, llegando a constituirse, en muy poco tiempo, en una modalidad deportiva más, con federaciones nacionales e internacionales, con reglamentos y competiciones al más alto nivel.

Asimismo, tendríamos que situar también en esta misma órbita al 'Aeróbic' y todo un cúmulo de actividades derivadas del mismo (como el 'Aerostep' y el 'Step', el 'Aerofitness' y el 'Fitness', el 'Cardiobox' y el 'Cardioball', el 'Body-Pump', el 'Bodytonic', el 'Aquaerobic 'y el 'Aquafitness', el 'Funkyjazz', el 'Spinning', el 'Streching', el 'Hip Hop', etc.), en todas las cuales la música desempeña, como en los 'Bailes de Salón', un papel fundamental.

La Psicomotricidad o Educación Física de Base también ha seguido este mismo camino. Le Boulch, Picq y Vayer, Lapierre y Aucouturier, Rossel, Lagrange, Gazzano, etc., incluyen en sus métodos, con mayor o menor acento, la utilización de la música y de las danzas.

Por otra parte cabría decir que no conocemos apenas un método de Expresión Corporal que no utilice como medio y soporte la música.

En cuanto a las aportaciones de la aplicación de la música en las clases de Educación Física en la actualidad, nos parecen significativas las de Conde, Martín y Viciana (1997) y el propio Conde (1998), esta vez ya en solitario, quienes exponen basándose en su experiencia, la conveniencia de generar aprendizajes motores a través de ella, desarrollado la idea de las Canciones Motrices, con la que nos sentimos muy identificados. En un contexto infantil, creemos que de una forma muy acertada, plantean reunir las dimensiones musical y motriz.

Asimismo nos parece interesante la aportación de Cuellar (1995), quien pone de manifiesto en una investigación realizada con el alumnado de tercer curso de estudios para Maestro cómo el uso de la música en las clases de una de sus asignaturas ha mejorado el nivel de diversión, el nivel de desinhibición, la interacción afectiva entre los compañeros así como con el profesor, la motivación y el nivel de aplicación del alumnado en el trabajo planteado; aspectos todos estos verificados a partir de un estudio comparativo en el que se aplicó un cuestionario diseñado al efecto.
Para terminar este breve apartado sólo faltaría señalar que la música se empleó de formas muy diferentes y variadas: Amorós incluía el canto y la danza entre sus actividades gimnásticas (los cantos tenían valor también por el efecto moral de sus palabras), y los asaltos se hacían a redoble de tambor (Amorós llegó a componer cantos bélicos para acompañar sus ejercicios); Björksten practicaba sus movimientos al ritmo de la música para que fueran enérgicos y ligeros, y además de la propia música utilizaba ritmos producidos con las manos y con los pies; Falk, Carlquist y Thulin empleaban los juegos, los cuentos-ejercicios y las rondas para dar alegría a sus clases, sobre todo en la gimnasia infantil, primaria y femenina; Tissié llegó a crear una orquesta escolar para acompañar sus ejercicios de gimnasia; Demeny incluía las danzas en la cuarta serie de ejercicios de su plan general de sesión, junto con las carreras y los rebotes; Hébert se valía del canto como ejercicio respiratorio y admitía las danzas por considerarlas ejercicios recreativos naturales; tanto Laban como Wigman emplearon la danza libre, y con ella la música, como recursos educativos; Bode fue uno de los más importantes promotores de la introducción y uso de la música en la Educación Física, y sostenía que los movimientos deben ser acompañados por música que incite a la expresión interna, y empleaba la voz, los instrumentos de percusión y el piano; Medau llegó a integrar plenamente la música en su método gimnástico, hasta el punto de usar los propios materiales portátiles (como por ejemplo la pelota, la maza o el aro) para marcar el ritmo, o manejar instrumentos musicales (como el pandero), como un aparato portátil más; Idla empleaba el siguiente proceso: hablar rítmicamente, hablar melódicamente, cantar y música preferentemente de piano; Romero y Dallo utilizaban bailes y danzas; Gaulhofer y Streicher, y Burger y Groll también hacían juegos cantados y danzados, y empleaban el piano, instrumentos de percusión (como el pandero), e incluso música garabada (discos y cintas magnetofónicas); Listello aconsejaba el uso del canto, de algunos instrumentos musicales, como la armónica, la flauta e instrumentos de percusión, y de las danzas folclóricas; Beckman empleaba, durante la totalidad de la sesión, música de jazz, barrel house, blues, boogie woogie, ragtime, rhytm and blues, bebop, cha-cha-chá, rock, etc.; Le Boulch llegó a publicar algunas grabaciones discográficas para su Método Psicocinético; etc.

\subsection{Funciones que puede cumplir la Música en las clases de Educación Física}

Basándonos en las ideas de Strachan y Hamilton (1989) hemos llegado a intuir las siguientes funciones que puede cumplir la música en las clases de educación física:

- Aumentar la motivación del alumnado hacia el trabajo motor. Esto se traduce en una mayor implicación por su parte hacia los contenidos que el profesorado desarrolla gracias al contexto de aprendizaje que la música genera. Es claro que la música es un elemento muy cercano a la infancia y la juventud.

- Servir como estímulo sonoro capaz de incidir en acciones organizativas propiamente dichas. 
- Generar un clima favorable desde el punto de vista afectivo entre los componentes del grupo, ya que crea un sentimiento de unidad, de deseo de compartir, una visión lúdica hacia la actividad.

- Aportar conocimientos en sí mismos, vinculados con la estructuración temporal y el ritmo.

- Dar apoyatura al desarrollo de determinados contenidos que necesariamente deben ser abordados con música. Sirven por tanto como soporte del movimiento.

\section{Clasificaciones de la Música y sugerencias discográficas}

\subsection{Clasificación general de la Música}

MÚSICA CULTA O CLÁSICA
Prehistoria e Historia primitiva
Civilizaciones avanzadas antiguas
Antigüedad tardía y temprana Edad Media
Renacimiento
Barroco
Clasicismo
Siglo XIX
Siglo XX
MÚSICA ÉTICA O FOLCLÓRICA
Continental
Nacional
Regional
MÚSICA LIGERA
Bandas sonoras
Blues
Disco
Electrónica
Funk
Hip-hop/Rap
Jazz
New age
Reggae
Rock

Aunque ésta no sería la única clasificación posible, sí parece la más ampliamente aceptada por los especialistas.

Sin embargo, a veces, este tipo de clasificaciones tan formales nos ofrecen poca ayuda en el momento de elegir una música para nuestras actividades, y otras más sencillas (música lenta o música rápida, música cantada o música instrumental, música clásica o música moderna, etc.), sin embargo, se manifiestan como mucho más pragmáticas.

\subsection{Sugerencias discográficas}

\section{MÚSICA CULTA O CLÁSICA}

\section{ANTIGÜEDAD TARDÍA Y TEMPRANA EDAD MEDIA}

$\checkmark$ Alfonso X "El Sabio": Cántigas de Santa María (Ensemble Unicorn [Naxos])

$\checkmark$ Anónimo: Carmina Burana

(Clemencic Consort/Clemencic [Harmonia Mundi])

$\checkmark$ Anónimo: Las mejores obras del canto gregoriano (Coro de Monjes de Santo Domingo de Silos [EMI])

\section{RENACIMIENTO}

$\checkmark$ Praetorius: Dances from Terpsichore (Westra Aros Pijpare/Farnlof [Naxos])

$\checkmark$ Varios compositores: At the sing of the crumhorn (Convivium Gothenburgense [Naxos])

$\checkmark$ Varios compositores: The glory of early music (Varios intérpretes [Naxos])

\section{BARROCO}

$\sqrt{ }$ Bach, J. S.: The Best of Bach (Varios intérpretes [Naxos])

$\checkmark$ Händel: The Best of Bach (Varios intérpretes [Naxos])

$\sqrt{ }$ Varios compositores: Baroque-Passion (Varios intérpretes [EMI])

\section{CLASICISMO}

$\sqrt{ }$ Beethoven: The Best of Beethoven (Varios intérpretes [Naxos])

$\sqrt{ }$ Haydn: The Best of Haydn (Varios intérpretes [Naxos])

$\checkmark$ Mozart: The Best of Mozart (Varios intérpretes [Naxos])

\section{SIGLO XIX}

$\checkmark$ Berlioz: The Best of Berlioz (Varios intérpretes [Naxos])

$\checkmark$ Schubert: The Best of Schubert (Varios intérpretes [Naxos])

$\checkmark$ Verdi: The Best of Verdi (Varios intérpretes [Naxos])

\section{SIGLO XX}

$\checkmark$ Bartók: The Best of Bartók (Varios intérpretes [Naxos])

$\checkmark$ Strauss, R.: The Best of Strauss (Varios intérpretes [Naxos])

$\checkmark$ Stravinsky: The Best of Stravinsky (Varios intérpretes [Naxos]) 


\section{MÚSICA ÉTNICA O FOLCLÓRICA}

\section{CONTINENTAL}

África: Percusiones africanas

(Guem [Chant du Monde])

$\sqrt{ }$ América: Spiritual songs, traditional chants \& flute music of the american indian

(Varios intérpretes [Proper/Retro])

$\sqrt{ }$ Asia: Poems Of Thunder: The Master Chinese Percussionist(Varios intérpretes [Naxos])

\section{NACIONAL}

España: Antología del Folklore Musical de España (Varios intérpretes [Recopilado por Manuel García Matos] [Hispavox])

$\checkmark$ Celta: The Best of The Chieftains (The Chrieftains [Columbia])

$\checkmark$ Portugal: Amália Rodrigues \& The History of Fado (Varios intérpretes [Recording Art Dejavu Retro Gold Collection])

\section{REGIONAL}

Andalucía: Antología del Cante Flamenco (Varios intérpretes [Hispavox])

$\checkmark$ Andalucía: Camarón - Antología (Camarón [Philips])

$\checkmark$ Andalucía: Paco de Lucía-Antología (Paco de Lucía [Philips])

\section{MÚSICA MODERNA (I)}

\section{BANDAS SONORAS}

$\checkmark$ Bernstein: West Side Story

(Bernstein [Deutsche Grammophon])

$\sqrt{ }$ Jarre: Doctor Zhivago \& Ryan's Daughter (Jarre [Columbia])

$\checkmark$ Varios compositores: Las mejores canciones de cine. Vol 1 y 2 (Varios intérpretes [Sony])

\section{BLUES}

$\sqrt{ }$ Varios compositores: Greatest Blues (Varios intérpretes [Disky])

$\checkmark$ Varios compositores: Play Me The Blues (Varios intérpretes [Weton-Wesgram])

$\checkmark$ Varios compositores: The Ultimate Encyclopedia of American Blues Classics (Varios intérpretes [The Gold Collection])

\section{DISCO}

$\sqrt{ }$ Varios compositores: Disco Estrella: Lo que más se baila en el Caribe y lo que más se baila en Ibiza (Varios interpretes [Vale Music])

$\checkmark$ Varios compositores: Disco Fever (Varios interpretes [Weton-Wesgram])

$\checkmark$ Varios compositores: Paioneer - The Album (Varios intérpretes [Blanco y Negro])

\section{MÚSICA MODERNA (II)}

\section{ELECTRÓNICA (bakalao y similares)}

$\checkmark$ Varios compositores: Blanco y Negro Mix (Varios intérpretes [Blanco y Negro])

$\checkmark$ Varios compositores: Las mejores canciones Dance (Varios interpretes [Blanco y Negro])

$\checkmark$ Varios compositores: Techno House Festival (Varios intérpretes [Vale Music])

\section{FUNK}

$\checkmark$ Varios compositores: Black Plosion (Varios intérpretes [Charly])

$\checkmark$ Varios compositores: In Yo' Face! The History Of Funk: Vol. 1-8 (Varios intérpretes [Rhino])

$\sqrt{ }$ Varios compositores: Mega Funk (Varios intérpretes [Wagram])

\section{HIP-HOP / RAP}

$\sqrt{ }$ Varios compositores: $4 \times 4$ Hip-Hop (Varios intérpretes [Avoid])

$\checkmark$ Varios compositores: 100\% Rap (Varios intérpretes [TCD])

$\checkmark$ Varios compositores: Lyricist Lounge. Vol. 1 (Varios intérpretes [Rawkus])

\section{JAZZ}

$\checkmark$ Varios compositores: Jazz Guitar Magic (Varios intérpretes [The Gold Collection])

$\checkmark$ Varios compositores: The History of Jazz: Vol. 1-4 (Varios intérpretes [Capitol])

$\checkmark$ Varios compositores: The A-Z Encyclopedia of Jazz Classics (Varios intérpretes [The Gold Collection])

\section{NEW AGE}

$\checkmark$ Varios compositores: Diálogos con la Música: Vol. 1 y 2 (Varios intérpretes [RCA])

$\checkmark$ Varios compositores: Lo Mejor de la Música New Age (Varios intérpretes [RBA])

$\checkmark$ Varios compositores: Narada-Slowease Collection (Varios intérpretes [Narada])

\section{REGGAE}

$\checkmark$ Bob Marley: Bob Marley \& The Wailers (Bob Marley [Dejavu Retro Gold Collection])

$\checkmark$ Varios compositores: Rasta Reggae (Varios intérpretes [Weton-Wesgram])

$\checkmark$ Varios compositores: The Best of Jimmy Cliff (Jimmy Cliff [Mango])

\section{ROCK}

$\checkmark$ The Beatles: The Beatles/1962-66 (The Beales [EMI])

$\checkmark$ Varios compositores: Las 100 canciones más Rolling de la historia (Varios intérpretes [EMI])

$\checkmark$ Varios compositores: The Greatest Rock \& Roll Party Ever (Varios intérpretes [DISKY]) 


\section{OTRAS}

\section{Canciones y cuentos infantiles}

Varios compositores: Clásicos Divertidos 1 y 2 (Varios intérpretes [Philips])

$\sqrt{ }$ Varios compositores: El mejor álbum de relajación del mundo. Vols. 1 y 2 (Varios intérpretes [EMI])

En este momento sería necesario recordar que la música es una actividad cultural muy viva y en continua evolución, por lo que si no estamos en constante renovación, sobre todo en lo relativo a su vertiente moderna, corremos el riesgo de quedarnos rápidamente anticuados.

\section{Sistematización del uso de la} Música en las clases de Educación Física y sugerencias musicales

La música es un recurso muy accesible, barato y de fácil utilización. Nos puede servir para crear ambientes determinados, acompañar diversas actividades o estimular la aparición de emociones, estados de ánimo, ideas, imágenes mentales, sensaciones, sentimientos, etc.

Entendemos que no se trata de utilizar la música en cualquier situación y de forma indiscriminada. Muy al contrario, su uso requiere darle el valor adecuado en cada contexto: como música de fondo; como estímulo sonoro capaz de llamar la atención en determinado momento; como soporte al cual adecuar el movimiento; etc. También se hace necesario conocer el tipo de música más conveniente en cada caso. Desde este punto de vista interesaría que el profesorado conociera un repertorio más o menos extenso de obras.

Con esta perspectiva pasamos a sistematizar el uso que se le puede dar a la música en las clases de Educación Física.

Iniciaremos esta tarea por exponer los diferentes usos que puede tomar la música en este sentido:

- Como ambiente de fondo: En estos casos pretenderemos que el soporte musical no tenga protagonismo, simplemente servirá para enriquecer una situación. Puede ser muy útil para recibir de una forma agradable y estimulante al alumnado antes de comenzar la sesión o a modo de toma de contacto y presentación de la sesión. En este caso podemos utilizar para los pequeños músicas populares y tradicionales o de los programas televisivos infantiles del momento; para el alumnado de más edad, ESO y Bachillerato, música moderna animada, en castellano como Jarabe de Palo, Mecano, Maná o La Oreja de Van Gogh, o en otras lenguas como The Beatles, Chuck Berry, Eric Clapton, Pink Floyd, etc., a un volumen medio, lo suficientemente alto como para que se escuche, pero sin que nos moleste al hablar con ellas y ellos. También puede servirnos para darle al alumnado ciertas concesiones cuando de jamos que sea él quien aporte la música que desea en determinados momentos. El/la alumno/a preadolescente y adolescente se encuentra muy vinculado a formas musicales que identifica como parte de su mundo. Dejarles que sean ellos/as quienes la seleccionen y la aporten a la clase es de gran valor. En estos casos debemos implicar a todos/as los alumnos y alumnas, utilizando en este caso un turno rotativo. Esto nos permitirá además conocer mejor sus gustos y no quedarnos anticuados.

- Como recurso organizativo la música también puede ser una gran ayuda. En este caso subir y bajar el volumen de forma significativa será la llamada de alerta ante un cambio de situación. Cuando queremos que el alumnado pase de estar realizando cualquier actividad a reunirlo para que nos escuche ante una explicación; para una más rápida organización ante una próxima tarea; etc. Sería precisamente el punto de inflexión ante lo que Siendetop (1999) denomina "transición". En este caso sugerimos blues, étnica, jazz y rock animado y refrescante (Beach Boys, Benny Goodman, Louis Armstrong, percusionistas, Santana, Scott Joplin, etc.) Dependerá en cualquier caso del contenido concreto que se esté desarrollando.

En este mismo contexto organizativo la música podría aparecer asociada a consignas concretas: cuando pare la música cambiamos de pareja; cuando cambie la música comenzamos el ejercicio; cuando inicie la música comenzamos el trabajo propuesto; cuando haya una pausa en la música cambiamos el espacio de actividad, o aprovechamos para descansar... Son muchas las posibilidades existentes de asociar datos referidos a la música con cuestiones organizativas. Esto contribuye a facilitar este tipo de trabajo que desgasta tanto al profesorado y que en definitiva incide en el buen desarrollo de la clase.

- Como recurso capaz de aumentar la motivación en el alumnado hacia el trabajo que esté desarrollando, bien sea implicándole en un trabajo intenso, bien en un trabajo expresivo y/o comunicativo, o bien para animarle en los primeros momentos de la sesión en los que se hace necesario un alto grado de interés.

Tendría este mismo valor ante actividades que reclaman tranquilidad, sosiego, interiorización e introspección, en muchos casos asociado a lo que conocemos como "vuelta a la calma" dentro de la sesión, o ante contenidos específicos con estas demandas. En estos casos suele dar bastante buen resultado la música clásica más lenta (Albinoni, Bach, Beethoven, Grieg, Mozart, Pachelbel, Vivaldi, etc.), comenzando a un volumen medio para ir poco a poco bajándolo hasta que se haga imperceptible.

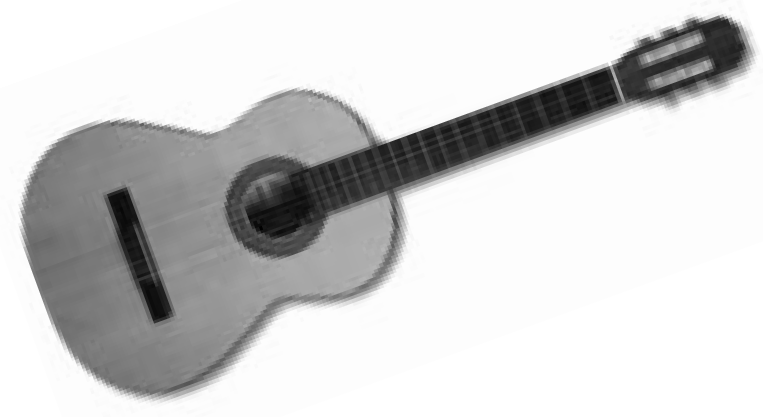


La música es capaz de contribuir a generar estos y otros muchos estados, siempre y cuando reúna las condiciones oportunas para ello.

Esto se pone de manifiesto también ante contenidos en los que trabajar la condición física con cierta intensidad, sin música pensada para ello, resultaría monótono y tedioso. Las músicas disco, electrónica, funk, hip-hop/rap, reggae y rock serían adecuadas (Dylan, King, Morrison, The Rolling Stones, The Waterboys, etc.).

También sería pertinente en aquellos momentos en los que expresar un sentimiento o una emoción se ve facilitado gracias al uso de una música estimulante. como la de jazz o la new age (Benson, Christian, Mertens, Reinhardt, Story, etc.).

Igualmente encontramos que la música cobraría este valor ante contenidos en los que hay que crear un ambiente idóneo para iniciar el trabajo. De esta forma se podría comenzar el calentamiento en un espacio cubierto acompañado: de música divertida, del tipo disco, electrónica, funk, hip-hop/rap, reggae o rock; canciones movidas de películas famosas (Billy Elliot The Full Monty, El Graduado, Pretty Woman, etc.); o empezar con danzas muy dinámicas que sirvan de trabajo introductorio, como las danzas del mundo. También cumpliría esta misión ante propuestas de desinhibición donde una música alegre, de ritmo muy marcado y capaz de subir el ánimo sería de gran utilidad.

Además podemos diseñar circuitos de condición física basados en soporte musical, en este caso la música cumpliría dos funciones: motivar al alumnado ante la ejecución; y servir de pauta organizativa en los cambios de una estación a otra.

- Como soporte necesario sobre el que se apoya el movimiento adaptándose en todo momento a ella. Es el caso del aprendizaje de una danza que necesariamente se hace con una música concreta (danzas del mundo o danzas populares); las canciones motrices sobre las que ir escenificando la letra de ellas; el caso del Aeróbic en todas sus modalidades o los diferentes bailes de salón que actualmente están cobrando protagonismo como aprendizaje motor en las clases de Educación Física. En este caso la música juega un papel esencial.

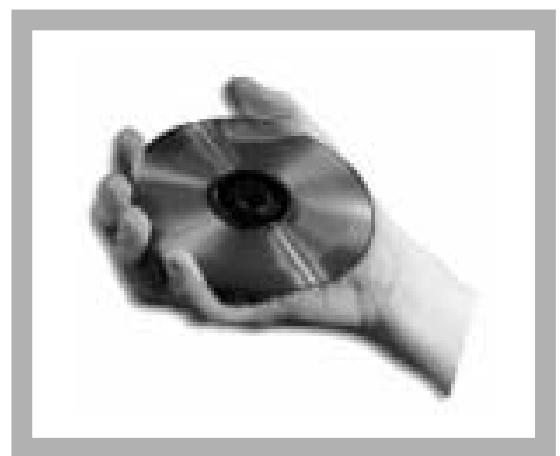

Si recorremos los diferentes bloques de contenido que nos platea el currículo oficial para las diferentes etapas de la escolaridad obligatoria podemos identificar aquellos contenidos que bien podrían ser abordados con soporte musical en las clases de Educación Física. Pasamos a continuación a hacer propuestas en relación a los mismos:

$\checkmark$ En la etapa de Primaria el bloque de contenido 'El cuerpo: imagen y percepción' nos sugiere el siguiente uso de la música ante los siguientes contenidos:

Los propios de relajación necesitan música tranquila, que invite a generar este estado corporal; incluso estimular el contraste entre tensión y relajación con dos tipos de música enfrentadas y por consiguiente por el estado tan diferente que despierta en el alumnado. También en trabajos de exploración y toma de conciencia de las posibilidades corporales la música podría ser un estímulo sugerente en este sentido. Las canciones motrices que aludan al cuerpo, a las partes de éste y a las posibilidades de movimiento que despliegan cada uno de los segmentos serían de gran apoyo ante estos trabajos. Las retahílas y canciones populares y tradicionales pueden ser muy adecuadas.

También la lateralidad podría asociarse a situaciones musicales, o bien a fragmentos de canciones que aludan a cada segmento o bien diferentes tipos de música que se asocien a cada hemicuerpo.

En los contenidos específicos de percepción temporal y espaciotemporal cobraría gran protagonismo las marchas, polcas, polonesas, valses de Strauss y danzas populares y tradicionales.

En cuanto al bloque de contenido 'El cuerpo: habilidades y destrezas' encontraríamos gran implicación con la música en lo que res-

- Como contenido específico.

Esto es sobre todo claro ante contenidos de ritmo o de estructuración temporal, cuando nos proponemos explicar por ejemplo lo que es el pulso, el acento o el compás. Estos aprendizajes se plantean de forma vivencial a través del movimiento, pero siempre necesitan del soporte musical para hacerlos más accesibles. La percusión y la música con ritmo muy marcado cobran un gran sentido en estos casos. Podríamos recomendar en este sentido bien música étnica de percusión, o bien música moderna con el ritmo muy marcado, como la disco, la electrónica, la funk, la hip-hop/rap, la reggae o la rock. pecta a las canciones motrices, en concreto a las canciones de corro donde los desplazamientos específicos, los giros y las posiciones cobran gran interés, sobre todo en los cursos más bajos de Primaria.

La adecuación del movimiento a estimulaciones sonoras como trabajo específico de coordinación también reclamaría necesariamente el uso de la música; nos estamos refiriendo tanto al trabajo global como al segmentario mediante botes o golpeos.

Respecto al bloque de contenido 'El cuerpo: expresión y comunicación' parece que es el que más reclama el apoyo musical. 
El trabajo concerniente a la exploración de los recursos corporales, en este caso con intención expresiva, encontraría una gran apoyatura en la música. Fomentar la actitud de desinhibición, tan idónea para estimular las situaciones expresivas y comunicativas también serían adecuadas mediante el uso de la música. Las calidades de movimiento son fácilmente estimuladas mediante músicas seleccionadas al efecto, que inviten a generar cada una de ellas. Pantomimas que puedan surgir de forma improvisada a partir de músicas concretas; diálogos corporales que nacen a partir también de soporte musical, etc.

La realización de pasos concretos o de danzas estructuradas por otra parte, así como la creación de coreografías o incluso fomentar danzas más libres, fruto de la expresión del mundo interno es fácil si la música invita a ello.

En este caso la variedad de músicas posibles de uso es muy extensa. Señalamos además como aportación al margen de la música propiamente dicha la existencia de CDs donde se aporta gran cantidad de sonidos y ambientaciones diferentes que pueden ser de gran utilidad: una tormenta, un establo de animales, una ciudad, una fábrica, etc. No se trata precisamente de música pero los señalamos porque pueden ejercer las mismas funciones ante este tipo de contenidos.

Con respecto al bloque de 'Los juegos' la música se asocia a aquellos de corte popular que se han puesto en práctica a través de la tradición asociados a canciones concretas. En estos casos las canciones también surgirían del propio alumnado; además proponemos también la música étnica y moderna.

$\checkmark$ Con relación a la etapa de Secundaria obligatoria encontramos que la música podría tener un gran protagonismo ante los siguientes contenidos:

Con respecto al bloque de contenido 'Condición física y salud' la música puede ser de gran utilidad para trabajar acondicionamiento físico de diferentes formas (circuitos: Aeróbic; Sesiones específicas que recuerden las prácticas comerciales de Fitness; calentamientos de diferentes tipos; Relajación; etc.) Debe estimular el tipo de trabajo que queramos generar. Al acondicionamiento físico le van las músicas disco, electrónica, funk, hip-hop/rap, reggae y el rock. Si queremos que el nivel de activación sea muy alto utilizaremos disco, electtrónica, funk, hiphop/rap, o seguiremos la estrategia de usar música no tan rápida utilizada a contratiempo, lo cual supone doblar el número de bits para generar una mayor velocidad en la ejecución de movimiento. Para relajación lo más adecuado sería el uso de baladas, música clásica y new age.

Respecto al bloque de contenido 'Juegos y deportes' se puede utilizar para montajes gimnásticos; para trabajos de investigación relacionados con la coordinación y el equilibrio. Músicas de bandas sonoras de películas pueden ser útiles en el primer caso y de jazz en el segundo. Además se puede utilizar la música para ambientar, como atmósfera de fondo cuando se aborden juegos populares y tradicionales de diferentes zonas geográficas.
El bloque de contenido 'Ritmo y expresión' es el que más se presta al uso de la música: los trabajos de investigación y exploración; los contenidos relacionados con el ritmo, con las calidades de movimiento; el uso de las danzas, tanto estructuradas como inventadas. En este caso las mismas sugerencias que hemos aportado para este bloque en el ámbito de Primaria podrían servir.

Respecto al bloque de contenido 'Medio natural' se propone el uso de música que provenga del alumnado, proponer al alumnado cantar mientras se realicen actividades en la naturaleza, siempre y cuando sea adecuada la compatibilidad entre las actividades.

\section{Procedimientos para la selección y utilización de la música en las clases de Educación Física}

En ocasiones necesitamos una música con unas peculiaridades muy concretas con intención de dar respuesta a nuestros intereses. En este caso saber cuáles son esas características es el punto de partida. Una vez establecidas, las sugerencias que exponemos a continuación van en la línea de cómo poder conseguirlas, cómo clasificarlas y cómo utilizarlas en las clases.

En términos generales, las reacciones frente a una misma música suelen ser bastante similares, por ejemplo un ritmo rápido incita al movimiento y a los desplazamientos, mientras un ritmo lento lo hace a la relajación. Pero también es cierto que mientras que a algunas personas la música clásica les parece excitante y emocional, otras por el contrario la encuentran aburrida y monótona; mientras que algunas creen que la música étnica tiene la fuerza de la pureza y la frescura de la autenticidad, otras opinan que es demasiado elemental y senciIla; mientras que para algunas el jazz y el rock representan la desinhibición, la energía, la rebeldía y la sensualidad de la juventud, para otras no son más que una sucesión de ruidos y ritmos atropellados; etc.

Por otra parte, la misma persona no reacciona siempre igual frente a la misma música, sino que está condicionada por el estado de ánimo, por su nivel de fortaleza o cansancio, etc.

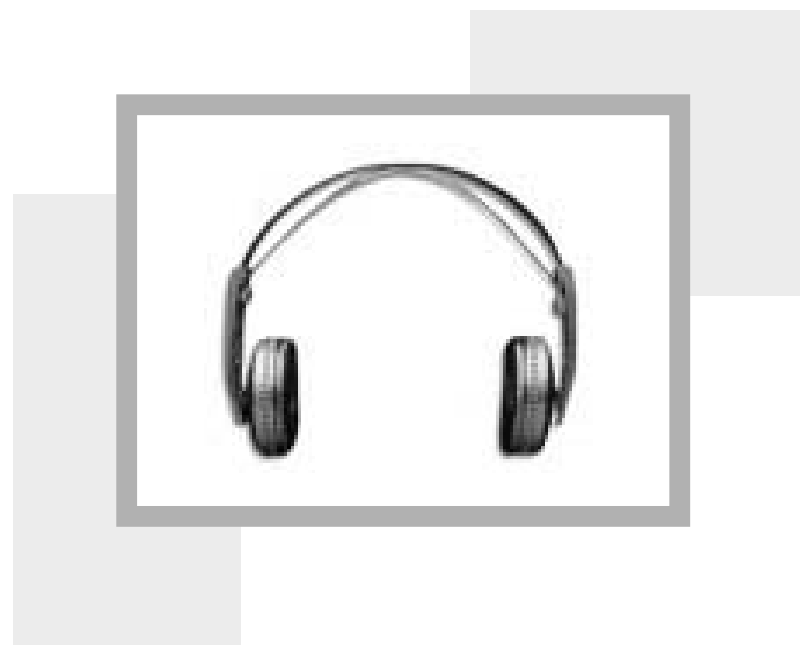


En la mayoría de los casos, por contagio social, sobre todo al principio, la música clásica tiende a provocar movimientos derivados del ballet, mientras que la música étnica y moderna generan movimientos de danza de discoteca, aunque después, y poco a poco, estos comportamientos van remitiendo y comienzan a aflorar movimientos mucho más naturales y creativos.

$A$ veces es conveniente utilizar músicas conocidas, para que el grupo se sienta cómodo y motivado, mientras que en otras ocasiones será muy interesante emplear músicas totalmente desconocidas, no sólo por ser infrecuentes, sino incluso por pertenecer a culturas muy distantes a la nuestra, para sorprender al alumnado e invitarle a la creatividad. Por lo tanto, todas estas cuestiones habrán de tenerse en cuenta, en relación con la utilización de la música como medio de estimulación externa durante las sesiones de Educación Física.

También es necesario poner atención a la velocidad de la música en función de la respuesta motriz que intentemos conseguir (ambientar, estimular, relajar, etc.)

Para ambientar se puede utilizar música new age, para estimular recomendamos música moderna con tiempos rápidos, según la terminología musical, de allegretto a prestisimo, y para relajar los tiempos lentos, de adagio a grave.

Así mismo, también hay que prestar especial atención a la intensidad o volumen de la misma, pues si bien puede molestar si se pone demasiado alta, también puede crear dificultades e incomodidad, por el esfuerzo que hay que hacer para escucharla si apenas es audible, por lo que se habrá de cuidar de ponerla a un volumen medio y agradable.

Hay que partir de la base, de que es prácticamente imposible que todas las músicas que utilicemos sean del agrado de todo el alumnado, en cualquier caso el mejor criterio a utilizar es el intentar satisfacer a la mayoría.

Tomadas en consideración estas ideas el siguiente paso sería localizarlas. Para ello se sugiere acudir a tiendas comerciales especializadas donde las músicas aparecen convenientemente clasificadas. Esto nos puede ayudar como punto de partida, y más todavía si es posible escucharlas a nuestra demanda. Las tiendas de segunda mano de música también pueden cubrir esta faceta con un coste mucho más bajo.

Hacerse con músicas a través de ca-

tálogos, del asesoramiento de personas entendidas en

este sentido, o simplemente el tener una actitud selectiva enfocada a nuestro objetivo cuando una música cae en nuestras manos nos permitirá hacernos con un repertorio musical.

Sería de gran utilidad cumplimentar unos datos muy simples sobre cada obra que tengamos, y adjuntarlos a cada una de ellas. Una pegatina en la carátula con este tipo de información sería de gran operatividad.

Los datos que deberíamos consignar podrían seguir las pautas que hemos dado con relación a la clasificación de la música, junto a otras tantas también comentadas en este artículo que servirían para catalogarla desde un punto de vista didáctico de la Educación Física para facilitar su selección posterior: Contenido con el que se asocia ('Condición Física', 'Relajación', 'Coreografías', 'Expresión del mundo interno': 'Adecuación a ritmos', 'Calidades de movimiento', 'Trabajo sensorial', 'Exploración corporal', 'Aeróbic', 'Bailes de salón', etc.), posible edad del alumnado (primer ciclo de primaria, ESO, etc.), forma de utilización (para animar, para relajar, para organizar, para bailar, para explicar el ritmo, para desinhibir, para recibir al alumnado, etc.)

El tener la música caracterizada bajo premisas didácticas nos permitirá seleccionarla para nuestras clases con gran facilidad. En este caso no hay más que acudir a la más adecuada.

También sería interesante, si no viniera en la carátula comercial, saber la duración de cada uno de sus temas y registrarla. Esto nos serviría de gran ayuda cuando tuviéramos que atender a duraciones concretas por las características del trabajo.

Conocerlo de antemano permite saber si tendremos que ir bajando el volumen progresivamente en un determinado momento en nuestra sesión o si será necesario grabar la pieza varias veces seguidas antes de llevarla a clase.

A partir de estos datos consignados en cada obra, sería cuestión de organizar el sistema de clasificación a la hora de guardarlo.

Evidentemente si no contamos con un número suficiente de obras es fácil caer en la reiteración y en la rutina. Recomendamos por tanto el ir haciéndonos poco a poco con un número suficiente de músicas de la mejor calidad posible.

En términos generales, podríamos decir que hay dos formas de llevar la música preparada para las sesiones, y cada una tiene sus inconvenientes y sus ventajas.

Hay quien prefiere llevar un estuche con los CDs que va utilizar durante la sesión, mientras que otras personas prefieren grabar de antemano toda la música en una cinta de casete.

El inconveniente de los CDses que tienes que estar metiendo y sacando los discos del aparato, con la correspondiente pérdida de contacto con el grupo,y la ventaja es que a veces hay que improvisar durante las sesiones y tienes a tu disposición otras músicas que puedes utilizar en todo momento.

Los inconvenientes de la casete son que hay que disponer de tiempo para su grabación y que la selección musical queda cerrada, teniendo menos posibilidades de improvisación en este caso.

Las ventajas son la comodidad y la facilidad de su utilización en la propia sesión ya que permite pararla y ponerla en marcha inmediatamente, sin tener que perder el contacto con el grupo al quitar y poner. 
Es cierto que en algunas ocasiones se hace necesario llevar la cinta preparada de casa porque responde a trabajos más elaborados; o bien porque hemos tenido que grabar varias veces seguidas de la mejor forma posible, sea porque hemos construido un material a base de mezclar músicas, dejar espacios vacíos en determinados momentos, o alternar fragmentos de diferentes piezas. Estas posibilidades dependerán de los recursos técnicos de los que dispongamos para elaborar este tipo de material.

Una vez escogida o elaborada la música para nuestra clase es necesario disponer de un equipo de sonido lo suficientemente potente como para que la música pueda ser bien escuchada en todo el espacio de que disponemos. Si fuera posible ubicarlo en mobiliario portátil tendríamos más posibilidades de utilizar la música en diferentes espacios de actividad. Un mando a distancia para su manipulación es un elemento hoy en día de fácil acceso y de gran utilidad para las clases de Educación Física.

\section{Conclusiones}

Desde un punto de vista metodológico nos parece oportuno expresar las siguientes conclusiones en relación con el uso de la música en las clases de EF:

$\checkmark$ Introducir música en las sesiones de EF resulta motivante para el alumnado.

$\checkmark$ Se puede comenzar por preparar alguna parte de la sesión con música, la que nos resulte más sencilla y paulatinamente ir ampliando el tiempo de música asociado a las clases.

$\checkmark$ Se puede comenzar por introducirla en alguna sesión y poco a poco ir aumentando el número de ellas con soporte musical a medida que vayamos cobrando experiencia en este sentido.

$\checkmark$ Debemos tener una actitud muy abierta y tolerante con el alumnado ante estas experiencias, ya que podemos encontrar que algunos/as de ellos/as inicialmente se sientan temerosos, avergonzados/as o inseguros ante estos planteamientos que les pueden resultar nuevos.

En este sentido utilizar la ubicación del alumnado de forma que no se miren directamente puede ser muy útil.

$\checkmark$ Debemos romper los estereotipos que todavía podrían existir respecto al uso del movimiento con música vinculado a una género. La mejor manera de hacerlo es con nuestra propia actitud, con naturalidad y con idénticas expectativas hacia ellos y ellas.

$\checkmark$ El ritmo de la música, si el profesorado da al alumnado las herramientas para manejarlo, permite adaptarlo a las capacidades motrices individuales. Ante una misma música se pueden interpretar distintos tempos a los cuales el alumnado puede adaptar su movimiento de forma individualizada.

$\checkmark$ Es conveniente crear una base de material, para lo cual conviene seguir unas pautas a la hora de seleccionar y "guardar" las músicas.

$\checkmark$ Dejarles que aporten ellos/as las músicas puede ser un aspecto motivacional importante.

\section{Referencias bibliográficas}

- BELTRÁN, R. (1991) Ambientación musical. Centro de formación RTVE: Madrid.

- BOURDIEU, P. (1998): La distinción. Criterio y bases sociales del gusto. Taurus: Madrid.

- BURGENER, L. (1973): L'éducation corporelle selon Rousseau et Pestalozzi. Vrin: París.

- CONDE, J.L. (1998): Canciones motrices. Paidotribo: Barcelona.

- CONDE, J. L., MARTÍN, C. y VICIANA, V. (1997): Las canciones motrices: metodología para el desarrollo de las habilidades motrices en Educación Infantil y Primaria a través de la música. Paidotribo: Barcelona.

- CUELLAR, M.M. (1995) La música como recurso didáctico en las clases de Educación Física: Estudio de un caso práctico (187-190) en Actas del II Congreso Nacional de Educación Física de Facultades de Educación y XIII de Escuelas Universitarias de Magisterio: Zaragoza-Jaca.

- FUBINI, E. (2002): La estética musical desde la Antigüedad hasta el siglo XX. Alianza: Madrid.

- LANGLADE, A. y REY, N. (1986): Teoría general de la gimnasia. Stadium: Buenos Aires.

a MERCURIAL, J. (1969-70): Arte jimnástico-médico. Rev. Citius, Altius, Fortius. Tomo XI-XII, 1348. Instituto Nacional de Educación Física y Deportes: Madrid.

口. MEYER, L. B. (2001) Emoción y significado en la música. Alianza: Madrid.

- MICHELS, U. (1992): Atlas de música, I. Alianza: Madrid.

- PARETI, L., BREZZI, P. y PETECH, L. (1981): Historia de la Humanidad. Desarrollo Cultural y Científico. Tomo 2. El mundo antiguo. Planeta/Sudamericana: Barcelona:

- REAL ACADEMIA ESPAÑOLA (2000): Diccionario de la Lengua Española. Espasa-Calpe: Madrid.

- SIENDETOP, D. (1999) Aprender a enseñar la Educación Física. Inde: Barcelona.

- STRACHAN, D. Y HAMILTON, I. (1989) Música y danza en la condición física. Unisport: Málaga.

- SWANWICK, K. (1992): Música, pensamiento y educación. Ministerio de Educación y Ciencia-Morata: Madrid.

- ULMANN, J. (1997): De la gymnastique aux sports modernes. Histoire des doctrines de li'éducation physique. Vrin: París.

- VARIOS (1964): Recreación y educación física deportiva. Kapelusz: Buenos Aires.

- VARIOS (1972): Gimnasia, deporte y juego. Kapelusz: Buenos Aires. 